\title{
Sociobiología y \\ psicología social. Nuevos términos para un viejo debate
}

ALBERTO BECERRA

Universidad Autónoma de Madrid

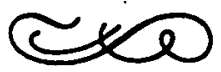

Cuando uso una palabra - dijo Humpty Dumpty, con cierto sarcasmo- significa exactamente lo que yo quièro que signifiquè: ni más ni menos.

El problema es - dijo Alicia - si tú puedes hacer que las palabras signifiquen tantas cosas diferentes.

LEWIS CARROL

El «humptydumptismo» es endémico en el discurso interdisciplinar, donde diferentes clases de especialistas usan las mismas palabras para significar cosas un poco diferentes. La enfermedad se vuelve difícil de diagnosticar, puesto que los enfermos a menudo son confundidos por lo que Quine llama «el supuesto implícito de la comprensión mutua". Los peligros son agudos en una congregación de viajeros que provienen de tierras tan diferentes ecológicamente como la sociología, la antropología, la psiquiatría, la biología y la psicología.

F. A. BEACH

Es simplemente perverso por parte de sus críticos, ignorar el minucioso y completo interaccionismo de la mayor parte de la teorización de la sociobiología humana.

I. A. VINE 
Con independencia de los posicionamientos teóricos que cada cual guarde ante la espinosa cuestión de "lo biológico", me permito sugerir al posible lector la conveniencia de abordar el presente tema de debate sobre Sociobiología y la Psicología Social como un intento de continuar la discusión abierta en un número anterior de nuestra revista («Explicaciones no psicológicas del comportamiento", S. Schachter, vol. 1, n. ${ }^{\circ}$ ), donde se planteaba de forma controvertida el papel que lo biológico, en su acepción más fisicalista (hormonas, estructuras nerviosas, etc.), puede jugar en la determinación relativa de ciertos comportamientos (e.g., síndrome de Tourette).

En una de las últimas afirmaciones de este trabajo, el propio Schachter planteaba sin ambages el punto central del problema: «Incluso ahora, no parece demasiado inverosímil sugerir que mucho de lo que consideramos relaciones interpersonales (los odios, pasiones, amores, agresiones y ansiedades) puedan con el tiempo entenderse mejor en términos bioquímicos que psicológicos» (p. 219). Aunque la frase pueda resultar excesiva, sobre todo para los escépticos de una psicología social de naturaleza multidisciplinar y para aquellos más partidarios de lo socio-simbólico en relación con el hombre social, la frase merece algunos comentarios que, entre otros, nos sirvan de introducción al "problema» de fondo del debate.

Cuando eminentes psicólogos sociales, como es el caso del que nos ocupa, llevan a cabo afirmaciones que, directa o indirectamente, sitúan en un primer plano la dimensión biológica del comportamiento social, lo primero que uno se pregunta es el porqué de la intermitente y persistente presencia de lo biológico como explicación en el marco de la psicología social institucional.

No es de recibo a estas alturas, discutir el hecho de que desde el antológico «manual» de Murchison (1935), monumental canto del cisne de una propuesta de psicología social que intentó apoyarse en modelos animales del comportamiento, así como en las elaboraciones más mecanicistas de inspiración darwiniana, nuestra disciplina ha seguido otras no menos inspiradas sendas, dentro de las cuales estímulos sociales, cogniciones, roles, normas, símbolos, culturas y demás, han cincelado con detalle y mimo ese «homo psicosocial» muy alejado (piénsese el lector en la intimidad) del «animal» que alguna vez todos hemos sospechado llevar dentro.

Sin embargo, y a pesar de los indudables logros de esta psicología social mayoritaria, una y otra vez aparecen discretos recordatorios (Brown, 1972; Tajfel y Fraser, 1978; Jiménez Burillo, 1981; Vine, 1983; entre otros) sobre el interés de considerar los conocimientos provenientes del campo biológico, en el estudio de lo psicosocial. Si bien podemos convenir en que tales llamamientos han demostrado poseer en la práctica escasa, que no nula, "capacidad de convocatoria", no es menos cierto, que dentro de nuestra disciplina se percibe en ocasiones, una cierta nostalgia (más determinante de melancolías que de acciones) por la pronunciada ausencia de cierto tipo de constructos que incorporen la «madre naturaleza» a nuestras explicaciones más genuinamente psicosociales.

Hace algo más de treinta años, afirmaba Solomon Asch (1952) que «los fenómenos psicológicos son, sin excepción, una función de los procesos orgánicos; percepciones e impulsos así como pensamientos y aspiraciones, tienen su contraparte en procesos particulares que ocurren en el individuo y 
en su sistema nervioso. Sea o no conocida y comprendida su base biofísica debe de ser supuesta. En ésta... nos ocuparemos de un punto de vista particular de los procesos biológicos del hombre, originados en la gran contribución de Darwin".

Treinta años después, un psicólogo con veleidades multidisciplinares, Vine (1983), comienza un trabajo teórico sobre sociobiología y psicología social afirmando que «... la psicología se encuentra sentada, poco confortablemente, en horcajadas sobre un sujeto con dos caras, teniendo que buscar la forma de mantener la visión de ambas al mismo tiempo. Por un lado, debemos vernos a nosotros mismos como un "sistema abierto", desde un punto de vista personal, como AGENTES responsables, íntimamente vinculados con otras personas en una realidad socialmente construida, poseyendo intencionalidad consciente y libertad subjetiva de elección para modificar aquellos significados, y trascender parcialmente nuestras situaciones de existencia. Pero también somos ORGANISMOS físicos, moldeados por nuestra biología heredada y por contingencias del ambiente sociofísico».

La yuxtaposición de ambas posiciones ilustra, bien a las claras, una cierta situación paradójica muy característica de la psicología social, a saber, que sin poder negar el estatus epistemológico de la biología del comportamiento, aquélla no ha sido capaz de integrar a ésta, salvo en contadas ocasiones (e.g., Ekman et al., 1972), dentro de los marcos interactivos que le son propios, habiendo desarrollado mucho más sus aspectos más puramente sociológicos y psicológicos, olvidándose del soporte biológico que los posibilita.

Muchas y, por otro lado, muy válidas razones existen para justificar que ello haya ocurrido así. Sin querer olvidar las irrefutables aportaciones de nuestras dos psicologías sociales, hay que convenir que las "tràsduciones» del pensamiento biológico al ámbito psicosocial han sido inevitablemente desafortunadas, al menos en sus expresiones más pretendidamente decisivas y generales, caso del Instintivismo de McDougall (1908) y de la utilización, parcialmente errónea y abusiva, de los modelos animales del comportamiento en el ámbito de la conducta humana (e.g., Murchinson, 1935).

En consecuencia, y por todo lo hasta aqui afirmado, la idea que muchos psicólogos sociales poseen sobre la explicación biológica, sobre su escasa utilidad heurística para el estudio del comportamiento social humano, pienso que procede fundamentalmente de un doble significado justamente atribuido al término.

En primer lugar, explicar biológicamente un fenómeno consistiría en atribuir alguna entidad interna al sujeto, ya sea estructura o proceso, de carácter bioquímico, hormonal $y / o$, sobre todo, nervioso la concurrencia de alguna conducta característicamente social. Sería ésta la dimensión fisicalista de explicación biológica, cuyas manifestaciones pioneras dentro de nuestra disciplina, podemos encontrarlas en la convencionalmente denominada Psicofisiología Social (Cacciopo y Petty, 1983). De su justificación epistemológica, la racionalidad de sus supuestos, así como de sus aportaciones, no hablaré aquí, en la medida en que no enicaja inicialmente con los términos del debate propuesto. Quede pues, su mención, como ilustración y constancia de la «difusa fascinación por lo natural», perceptible en algunos colegas. 
La segunda acepción de explicación biológica, muy próxima a los imperativos del presente debate, radicaría en la aplicación de la Teoría de la Evolución por Selección Natural (Darwin, 1859, 1871), al campo de la conducta social. Dos, fundamentalmente, fueron las ideas que con más entusiasmo y desacierto, se intentaron explorar desde nuestro campo (y no sólo desde él): La comunalidad de origen de estructuras y comportamientos de animales y hombres, y el determinante hereditario de ciertos patrones de comportamiento denominados instintos.

La primera de estas ideas, aunque moderadamente, ha tenido un cierto reconocimiento en nuestro ámbito, fundamentalmente gracias a la labor de intermediación de la Etología en relación con ciertos aspectos puntuales del comportamiento social (e.g., la noción de troquelado, Lorenz, 1972), sin olvidarnos de las aportaciones metodológicas de carácter observacional. Con todo, la filosofía subyacente al trabajo con modelos animales, según la cual el comportamiento humano era explicable en términos de los procesos conductuales de otras especies, resultaba excesivo en su pretensión reduccionista, generando por tanto mucha más desconfianza que entusiasmo.

Complementaria por muchos conceptos a la anterior, la noción de instinto reveló muy pronto, su nulo poder explicativo en relación a la conducta social humana, agravada por la mala comprensión que de la Teoría de la Evolución hace gala McDougall en su clasificación jerárquica de los instintos, pues situar en un distinto nivel respecto a la génesis de las emociones el instinto parental y reproductor, por ejemplo, es ignorar, en cierto modo, la función básica que desde el punto de vista de la teoría poseen los procesos intermedios de carácter emocional.

Este estado de cosas estructura actualmente el pensamiento de muchos psicólogos y psicólogos sociales, en relación al problema de las «explicaciones no psicológicas del comportamiento», y pienso que constituye el marco de referencia desde el que muchos colegas se han aproximado a la Teoría Sociobiológica.

Dicho marco de referencia se explicita en relación con la Sociobiología, considerando a ésta como una teoría de la determinación genética del comportamiento $y$, por tanto, como una reactualización, corregida y aumenta$\mathrm{da}$, de un periclitado instintivismo, todo lo cual, la hace incurrir en una excesiva ideologización con claros componentes racistas, sexistas, etc., y donde los aspectos interactivos y más específicamente humanos no se contemplan.

Aparte las razones históricas, ya expuestas, no voy a negar las suyas a los postulantes de estas posiciones críticas, convertidas al día de hoy en casi un estereotipo, frente a los postulados sociobiológicos; los mismos sociobiólogos (e.g., Wilson, 1980; Baras, 1982) contribuyeron inicialmente a fomentarlas con unas afirmaciones poco meditadas sobre el omnímodo poder explicativo de la «nueva síntesis» y poco cuidadosas con las exigencias teóricas y epistemológicas de las distintas ciencias sociales (e.g. Symonns, 1979).

Sin embargo, casi quince años después de la aparición de la archinombrada obra de Wilson, pienso que poseemos la suficiente información y que determinadas cuestiones se han debatido tan ampliamente, como para poder proponer una nueva «imagen» del edificio conceptual sociobiológico y adelantar, tentativamente, algunas formas de utilizar los constructos sociobiológicos en el estudio del comportamiento social humano. 
Ahora bien, cualquier propuesta en este sentido requiere la aclaración previa del significado exacto de uno de los supuestos sociobiológicos peor entendido $y$, en consecuencia, más sistemáticamente criticado; nos referimos naturalmente, en este contexto, al ubicuo problema del determinismo genético supuestamente postulado por los sociobiólogos más conspicuos.

Parece claro que las suspicacias y reticencias teóricas, que el determinismo genético preconizado por los sociobiólogos ha despertado entre los estudiosos de la conducta social, se basa fundamentalmente en el carácter de programación o determinación, directa o inflexible, que supuestamente los genes «ejercen» sobre determinados comportamientos, excluyendo absolutamente todas las posibles influencias de los múltiples procesos de socialización. Vistas así las cosas, no sería de apreciar diferencias explicativas importantes entre algunos de los innumerables instintos postulados, en su momento, desde un marco macdougalliano y los postulados sociobiológicos más recientes.

No espero sorprender a nadie si afirmo que este estereotipo intelectual sobre lo que la Sociobiología postula, es producto de la prevalencia de un mito cultural muy extendido (el mito del determinismo genético) y, sobre todo, de una apreciación inexacta de lo que es la teoría de la evolución en sí y en sus consecuencias para el estudio de la conducta social. Trataré de ilustrar brevemente estas afirmaciones.

Previamente creo que debemos establecer el acuerdo de que todos, tanto el que esto escribe como el que con generosidad me lea, compartimos hasta un punto una profesión de fe en el determinismo filosófico, en el sentido de creer en un fundamento material para nuestras acciones, de considerar que el comportamiento está predeterminado por causas materiales anteriores en el tiempo a su manifestación. Sobre esta base, podríamos convenir también que es indiferente, a priori, desde un punto de vista estrictamente gnoseológico, atribuir a los genes, el cerebro, o el ambiente la materialidad causal de un comportamiento concreto (téngase en cuenta que no son las prescripciones de prueba lo que aquí se discute).

Lo que en relación al tema de la Sociobiología rompe el consenso sobre el determinismo, es la influencia de lo que Dawkins (1982), sociobiólogo de postín, llama el «mito del determinismo genético", o la creencia en la imposibilidad de cambiar los caracteres supuestamente vinculados a los genes, mediante la educación, la cultura o la voluntad. Frente a este aserto Dawkins establece su alternativa:

"¿Por qué se consideran los determinantes genéticos más ineluctables, o más exculpatorios que los ambientales?... En principio, las causas genéticas y las ambientales no se diferencian entre sí. Hay influencias de ambos tipos que pueden ser difíciles de anular, pero fáciles si se aplica el factor adecuado. Lo importante es que no hay una razón general para creer que las influencias genéticas sean más irreversibles que las ambientes” (ibíd., pp. 151-152).

Se podrá o no estar de acuerdo con la idea principal del sociobiólogo, lo que ya resulta más difícil es no apreciar un cierto relativismo a la hora de valorar las influencias de los genes sobre el comportamiento. Pero por si existiesen dudas respecto a su posición, el autor nos aclara inmediatamente que:

"Cuando un genetista habla de un gen "para" los ojos rojos de la drosofila, no está hablando del cistrón que actúa como modelo para la síntesis del pig- 
mento rojo. Está diciendo implícitamente: hay variación en el color de los ojos de la población; en igualdad de condiciones, una mosca con este gen cuenta con más probabilidades de tener los ojos rojos que una mosca que carezca de él... Exactamente lo mismo sucede con el comportamiento» (ibíd., p. 159).

Y pasa a aclararnos lo que quiere decir:

$\mathrm{Si}$ alguien dijese que el sexo de una persona (factor claramente ligado a la existencia de cromosomas) ejerce una influencia causal, digamos sobre su habilidad musical o su afición a hacer punto, ¿qué significaría esto? Significaría que, en determinada población, $y$ en determinado ambiente, un observador que poseyese información sobre el sexo de un individuo podría hacer una predicción estadísticamente más certera sobre la habilidad musical de dicha persona que otro observador que ignorase su sexo. Subrayemos la palabra "estadísticamente", y añadamos, además, "en igualdad de condiciones". El observador podría contar con alguna información adicional -por ejemplo, sobre la formación o educación de la persona - que le llevase a revisar, o incluso anular, su predicción basada en el sexo. Si las hembras propenden estadísticamente más que los machos a disfrutar haciendo punto, ello no significa que todas las mujeres disfruten haciéndolo; ni siquiera la mayoría» (ibíd., p. 151).

Nada tengo que añadir a todo lo anterior, salvo insistir de nuevo en el carácter eminentemente estadístico con el que los sociobiólogos hablan de los comportamientos «ligados a los genes» y el reconocimiento expreso de su susceptibilidad a posibles influencias «no naturales». En consecuencia, seguir hablando de la Sociobiología como sinónimo de un determinismo genético decimonónico, carece de cualquier sentido inteligente. Sin embargo, relativizado su componente determinista, ¿por qué, insisten una y otra vez los sociobiólogos en "confundirnos" con constantes referencias a "genes para» el comportamiento $\mathrm{X}$ o el comportamiento $\mathrm{Y}$ ?

La respuesta conecta de forma inmediata con lo que son las prescripciones de la moderna Teoría de la Evolución y de la cual, como es sabido, proviene en sus desarrollos básicos la teoría Sociobiológica. Si bien éste no es el sitio para una pormenorizada descripción de la «síntesis evolucionista", interesa especificar algunas propuestas de la misma, para mejor comprender el modo de pensar sociobiológico.

En su sentido estricto, la noción de Evolución es caracterizada como cambios en la frecuencia génica de las poblaciones debidas a las interacciones que los organismos llevan a cabo con su medio ambiente, y tiene su correlato a nivel individual en los cambios paralelos producidos en los patrones de desarrollo, en las estructuras fisiológicas y en el comportamiento (Dobzhansky et al., 1980).

Consecuentemente a ello, cuando los sociobiólogos hablan de la selección natural como causa del comportamiento, desde un punto de vista exclusivamente evolucionista, están hablando de supervivencia y reproducción diferencial de genes y por tanto «si hablamos de la posibilidad de que un modelo de comportamiento evolucione por selección natural, tenemos que hablar de la variación genética en relación con ese modelo de comportamiento. Esto no significa afirmar que exista tal variación genética para cualquier modelo de comportamiento particular, sino sólo que ha debido de haber variación genética en el pasado, si queremos considerar el modelo de comportamiento como una adaptación darwiniana (Dawkins, ibíd., p. 156). 
Dicho lisa y llanamente, el párrafo anterior pone de relieve que la utilización del constructo gen en relación con la conducta, es un requerimiento lógico desde el punto de vista de la teoría de la evolución por selección natural, que no tiene por qué implicar ningún tipo de determinación estricta de ningún comportamiento, tal y como anteriormente se ha demostrado. Otra cosa es que los términos que reflejan un enfoque filogenético del comportamiento (seleccionismo génico), se tomen equivocadamente como indicadores de un enfoque ontogenético del mismo (determinismo genético). Creo que con lo dicho hasta aquí de ambos aspectos, hay más que suficiente para romper ciertos equívocos que tanto han lastrado hasta ahora la compensación ajustada de lo que la Sociobiología como teoría es. De todas formas, nada mejor que una declaración final de intenciones para despejar todas las dudas:

"Por supuesto, los sociobiólogos pueden ser individualmente acérrimos deterministas genéticos o no, y creer que los seres humanos están rigurosamente constreñidos por sus genes. Pueden ser rastafarianos, adventistas o marxistas. Pero nuestras opiniones particulares sobre el determinismo genético, al igual que nuestras opiniones... sobre religión, no tienen nada que ver con que utilicemos el lenguaje de "los genes para el comportamiento" cuando hablamos de selección natural. El determinismo, en el sentido de una ontogenia inflexible y de una trayectoria fija como un tranvía, está, o debería estar, a mil millas de nuestros pensamientos" (Dawkins, ibid., p. 161).

Parcialmente despejada la cuestión de lo que la sociobiología no es, me gustaría dedicar las líneas finales de este comentario a subrayar sus aspectos teóricos clavés en relación al estudio de la conducta social.

Para empezar no estaría de más recordar que la Sociobiología es una reformulación de la Teoría de la Evolución por Selección Natural de Darwin, la cual a su vez es, en sus aspectos básicos, una teoría de la interacción entre los individuos y su medio (no sólo medio natural, sino también medio social), a partir de la cual aparecen y evolucionan los comportamientos sociales adaptativos.

A diferencia de otros fallidos intentos de trasplantar los supuestos darwinianos al estudio de la conducta humana, tal y como ha sido el caso del instintivismo y, en menor medida, de las extrapolaciones etológicas, la Sociobiología provee un conjunto de modelos y de constructos teóricos sobre el comportamiento humano, que lejos, como hemos visto, de cualquier pretensión de hegemonismo genético, y tomados en su significado concreto, pueden resultar muy útiles a la hora de explicar determinados comportamientos sociales (Crawford, 1987).

Así, los modelos y conceptos de selección sexual, selección de parentesco, teoría de la historia vital, eficacia inclusiva, inversión parental, estrategias evolutivamente estables, altruismo recíproco, conforman una estructura teórica, potencialmente más explicativa que ninguna de las provenientes hasta ahora del campo biológico, y que en su aplicación al estudio de fenómenos comunicativos, socio-sexuales, prosociales, agresivos, etc., empieza a mostrar sus frutos dentro del ámbito de la Psicología Social; véanse, al respecto, los trabajos de Cunningham sobre altruismo, en el artículo de fondo de este debate; de Cunningham (1986) sobre atractivo físico; de Howard et al. (1987) sobre preferencias en la elección de compañero; de Sadalla et al. (1987) sobre dominancia y atracción sexual; las reflexiones teóricas de Krebs (1987) sobre el altruismo y del mismo Krebs y Miller (1985) 
sobre altruismo y agresión, por citar algunos de los últimos trabajos de psicólogos sociales llevados a cabo sobre supuestos sociobiológicos.

De todos estos trabajos se desprende una utilización de los desarrollos teóricos sociobiológicos en su dimensión predictiva (Crawford, 1987), donde todo un conjunto de hipótesis coherentes con el marco evolucionista, son sometidas a prueba a través de distintas técnicas, para su provisional comprobación o refutación. Pues conviene insistir de nuevo, que la Sociobiología ni es un neoinstintivismo con afanes puramente clasificatorios, ni un «revival» más brillante de la vieja filosofía etológica, por la cual el comportamiento animal debiera ser el espejo donde encontrar reflejado el comportamiento humano.

La sociobiologia, por contra, no es sino una teoría sobre los determinantes evolucionistas (que no genéticos) del comportamiento social humano, de su posible y relativa (que no inevitable) pervivencia en nuestros patrones de interacción cotidiana; su aspiración más sentida, descansa en la simple pretensión de poner a prueba sus asertos fundamentales y en el desarrollo más complejo de sus ideas y conceptos, nada más.

Todo lo manifestado hasta aquí, tiene su equivalente empírico en el trabajo de $M$. Cunningham que sirve de artículo de fondo para el debate. Todo él constituye una buena ilustración del empleo de los modelos teóricos sociobiológicos en relación a un problema tan psicosocial como el del altruismo. Las inteligentes aportaciones de los profesores Bernis, Varea, Peláez y Zaccagnini, contrapresan, como así debe ser, la presentación del «lado bueno" de la Sociobiología que conscientemente aquí he tratado de exponer.

\section{Referencias}

AsCH, S. E. (1952). Psicología social. Buenos Aires, EUDEBA (edición en castellano de 1964).

BARASH, D. P. (1977). Sociobiology and behavior. Nueva York, Elsevier.

BROWN, R. (1972). Psicología social. Madrid, Siglo XI.

CunNINGHAM, M. R. (1986). Measuring the physical in phisical attractiveness. Journal of Personality and Social Psychology, 50, 5, 925-935.

DARWIN, C. (1859). El origen de las especies. Madrid, EDAF (edición en castellano de 1985).

DARWIN, C. (1871). El origen del Hombre. Madrid, EDAF (edición en castellano de 1979).

Daw/KIns, R. (1982). El mito del determinismo genético. Revista de Occidente, n. 18-19, pp. 149-161.

Dobzhansky, T.; Ayala, F. J.; Stebbins, G. L., y Valentine, J. W. (1980). Evolución. Barcelona, Omega.

EKMAN, P.; FESEN, W. V., y EllswORTH, P. (1972). Emotion in the buman face. Nueva York, Pergamon.

HowARD, J. A.; BLUmSTEIN, P., y SCHWARTZ, P. (1987). Social or evolutionary theories? Some observations on preferences in human mate selection. Joumal of Personality and Social Psychology, 53, 1, 194-200.

JimÉnEZ BURILlo, F. (1981). Psicologia social. Madrid, UNED.

KREBS, D., y MiLlER, D. (1985). Altruism and aggression. En G Lindzey y E. Aronson (eds.): Handbook of Social Psychology (3.' ed.). Nueva York, Addison-Wesley.

KreBs, D. (1987). Altruism in biology and psychology. En C. Crawford, M. Smith y D. Krebs: Sociobiology and psychology. Hillsdale, LEA.

LORENZ, K. (1972). El comportamiento animal y humano. Barcelona, Plaza y Janés.

MCDOUGAL:, W. (1960). An introduction to social psychology. Boston, Lucen and Co.

MuRCHISON, C. (ed.) (1935). Handbook of social psychology. Worcester, Massachusetts, Clark University Press.

SAdalla, E. K.; KenRick, D. T., y Vershure, B. (1987). Dominance and heterosexual attraction. Journal of personality and social psychology, 52, 4, 730-738.

TAJEFEL, H., y FRASER, C. (1978). Introducing social psychology. Nueva York, Penguin.

SYMONS, D. (1979). The evolution of human sexuality. Nueva York, Oxford University Press.

VINE, I. (1983). Sociobiology and social psychology. British Journal of Social Psychology, vol. 22 , p. 1-11.

WILSON, E. O. (1975). Sociobiologia. Barcelona, Omega (edición en castellano de 1980). 